\title{
Optimum seismic fortification level forelectrical equipment in substation
}

\author{
Min Zhong ${ }^{1, a^{*}}$, Yuhan Sun ${ }^{1, b}$, Sen Lin ${ }^{1, c}$, Zhenlin Liu $^{1, d}$ \\ ${ }^{1}$ China Electric Power Research Institute, China \\ azhongmin@ epri.sgcc.com.cn, ${ }^{\text {b}}$ sunyuhan@epri.sgcc.com.cn, \\ clinsen@epri.sgcc.com.cn, diuzhenlin@epri.sgcc.com.cn
}

\begin{abstract}
Keywords: electrical equipment, optimum seismic fortification level, seismic reliability, failure classification, seismic fortification grading

Abstract. We determined the seismic fortification level of electrical equipment in this paper according to the features of seismic failures in substation, provisions about seismic fortification level standard, and decision about optimum seismic fortification for electrical equipment, we also classified the seismic fortification level according to seismic reliability calculations and reliability results, put forward a high, medium and low seismic fortification level system.
\end{abstract}

\section{Introduction}

Seen from earthquake hits home and abroad, one of the disastrous consequences is the extensive long-time power outage caused by the wrecked electrical equipment, which arouse people's consciousness on safeguarding the safety of power grid by boosting the seismic capacity of electrical equipment, which mainly depends on the seismic fortification level. Now the seismic design of electrical equipment in our country mainly refers to Code for Seismic Design of Electrical Installations(GB 50260 - 2013)[1],seismic fortification grade, and site parameters are taken from Seismic Ground Motion Parameter Zonation Map of China(GB 18306-2001)[2] and Code for Seismic Design of Buildings(GB 50011-2010)[3].

However, Seismic Ground Motion Parameter Zonation Map of China(GB 18306-2001) and Code for Seismic Design of Buildings(GB 50011-2010) are applicable for seismic design for ordinary construction project and a special building rather than electrical equipment because of their high universality, if classified in details as those for building structures, it shall be unfavorable for massive production of electrical equipment, so will design and selection for engineers, what's more, this may as well repeat the unnecessary seismic safety appraisal, postpone the joint debug and operation of equipment. For all above, some foreign countries and regions set out the combination of seismic ground motion parameter zonation map and divide into a high, medium and low grade system, which is more suitable for electrical equipment[4][5].

Hereby we defined the seismic failure degree for electrical equipment according to relative standards home and abroad, power grid optimum seismic fortification level decision-making method, and calculated seismic reliability results, discussed the grading of seismic capacity for electrical equipment, recommended the grading principle for our country's electrical equipment seismic fortification. 


\section{Seismic level in foreign related seismic codes for electrical equipment}

Generally, many foreign countries have established their seismic fortification grades for electrical equipment, including Japan, who has only one seismic fortification type, for small and narrow area of land, and relatively single type of earthquake.IEC62271-2 specifies three of high, medium and low grades, with seismic level equivalent to S2 earthquake magnitude, which requires a nuclear power station to safety shutdown, with annual exceeding probability $10^{-4}$. US IEEE693 also specifies three of high, medium and low grades, but its seismic fortification level is classified on the basis of 50-year exceeding probability2\%, shown as Tab. 1.

Tab.1 Comparison of seismic level in foreign related seismic codes for electrical equipment

\begin{tabular}{|c|c|c|c|}
\hline Foreign standard and code & & Seismic level & $\operatorname{PGA}(g)$ \\
\hline \multirow{5}{*}{$\begin{array}{l}\text { Japan Guide of Seismic Design for Electrical Equipment[6] } \\
\text { JEAG 5003-1998 }\end{array}$} & Porcelain & & \\
\hline & electrical & - & $0.3 \mathrm{~g}$ \\
\hline & equipment & & \\
\hline & Insulating & & \\
\hline & $\begin{array}{l}\text { bush of } \\
\text { transformer }\end{array}$ & - & $0.5 \mathrm{~g}$ \\
\hline \multirow{3}{*}{\multicolumn{2}{|c|}{$\begin{array}{l}\text { IEC62271-2:2003High-voltage switchgear and controlgear-Part 2: } \\
\text { Seismic qualification for rated voltages of } 72.5 \mathrm{kV} \text { and above }\end{array}$}} & $\begin{array}{l}\text { AG2: low to } \\
\text { medium intensity }\end{array}$ & $0.2 \mathrm{~g}$ \\
\hline & & $\begin{array}{l}\text { AG3: medium to } \\
\text { high intensity }\end{array}$ & $0.3 \mathrm{~g}$ \\
\hline & & $\begin{array}{l}\text { AG5: high to high } \\
\text { high intensity }\end{array}$ & $0.5 \mathrm{~g}$ \\
\hline \multirow{3}{*}{\multicolumn{2}{|c|}{ USA substation seismic design code IEEE Std 693-2005 }} & Low level: $<0.1 \mathrm{~g}$ & $0.1 \mathrm{~g}$ \\
\hline & & $\begin{array}{c}\text { Medium } \\
\text { level:0.1g 0.5g }\end{array}$ & $0.25 \mathrm{~g}$ \\
\hline & & High level: $>0.5 \mathrm{~g}$ & $0.5 \mathrm{~g}$ \\
\hline
\end{tabular}

\section{How to specify the optimum seismic fortification level for electrical equipment}

3.1 Objective function of optimum seismic fortification level. The optimum seismic fortification level of power grid is the min. value calculated by objective function considering short-term investment (construction cost) and long-term income (loss expectation), that is

$$
\mathrm{W}\left(\mathrm{I}_{\mathrm{d}}\right)=\mathrm{C}_{\min }\left(\mathrm{I}_{\mathrm{d}}\right)+\mathrm{L}\left(\mathrm{I}_{\mathrm{d}}\right) \rightarrow \min
$$

Where,W,Cmin and $\mathrm{L}$ are respectively total investment, lowest construction cost and loss expectation for design $\overline{\mathrm{x}}\left(\mathrm{I}_{\mathrm{d}}\right)$, all of them are functions of single variable Id. For each seismic fortification intensity $\mathrm{Id}$, the design of lowest construction cost for structure $\overline{\mathrm{x}}\left(\mathrm{I}_{\mathrm{d}}\right)$ is unique, so both formula (1) and formula (2) are equivalent

$$
\mathrm{W}\left(\mathrm{I}_{\mathrm{d}}\right)=\mathrm{C}_{\min }\left(\mathrm{I}_{\mathrm{d}}\right)+\mathrm{L}\left(\mathrm{I}_{\mathrm{d}}\right) \rightarrow \min
$$

Because other designs themselves have some factors of waste, considering the optimization of objective functions, the seismic fortification with the lowest construction cost is feasible. 
3.2 Method for solving the lowest construction costcurve. There are two methods for solving lowest construction costcurve Cmin- $\operatorname{Id}\left(\right.$ i.e., function $\mathrm{C}_{\min }\left(\overline{\mathrm{x}}\left(\mathrm{I}_{\mathrm{d}}\right)\right)$ )).

\section{(1) Precise}

First, under the specified seismic fortification intensity Id, resolve the structure design $\overline{\mathrm{x}}\left(\mathrm{I}_{\mathrm{d}}\right)$, let the construction cost meet with the formula below

$$
\mathrm{C}_{\text {min }}\left(\overline{\mathrm{x}}\left(\mathrm{I}_{\mathrm{d}}\right)\right) \rightarrow \min
$$

and all applicable provisions and requirements.

Then work out the respective lowest construction cost Cmin with different Ids to get several points on function $\mathrm{C}_{\min }\left(\overline{\mathrm{x}}\left(\mathrm{I}_{\mathrm{d}}\right)\right)$ orcurve Cmin-Id, and lowest construction cost curve Cmin-Id by using a statistical regression method, shown as Fig.1.The lowest construction cost $\mathrm{C}_{\min }\left(\overline{\mathrm{x}}\left(\mathrm{I}_{\mathrm{d}}\right)\right)$ increases with the increasing of seismic fortification intensity.

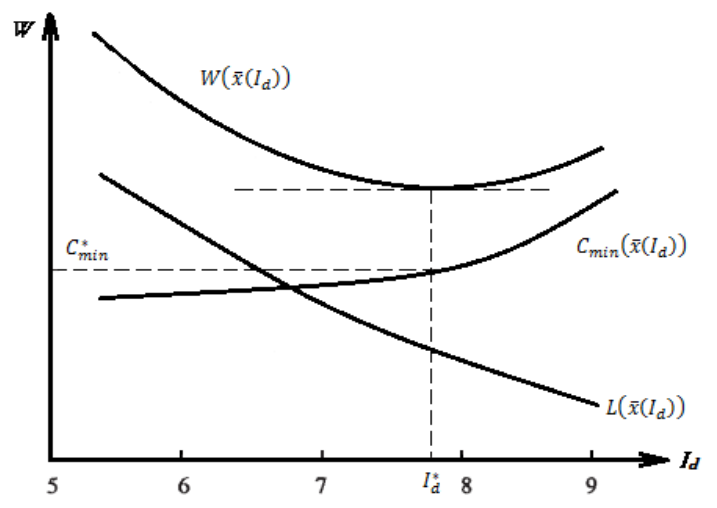

Fig.1 optimum seismic fortification level decision-making graph

\section{(2) Simplified}

Although it is easy to calculate function $\mathrm{C}_{\min }\left(\overline{\mathrm{x}}\left(\mathrm{I}_{\mathrm{d}}\right)\right)$ (i.e.,Cmin-Id curve ), quite a lot workload shall be paid for, to keep stay away from this case, substitute the lowest construction cost curve Cmin-Id with empirical curve C-Id for giving structure cost and seismic fortification intensity according to designed and calculated empirical and statistical data. The simplified method can calculate the real structure cost $\mathrm{C}\left(\mathrm{I}_{\mathrm{d}}\right)$ in details according to normal method (e.g., budgeting) according to seismic fortification intensity Iddesign, this shall be more suitable for the actual situation.

3.3 Loss expectation of electrical equipment. The loss of power grid under type-Bifailure can be expressed in a formula below

$$
\mathrm{D}_{\mathrm{i}}=\mathrm{D}_{\mathrm{i}}^{(1)}+\mathrm{D}_{\mathrm{i}}^{(2)}
$$

Where, $D_{i}^{(1)}$ is the direct loss from the failure of structure itself, $D_{i}^{(1)}$ is the indirect loss accompanied with the structure. For total loss of structure under multi-level failure criterion, it can be worked out with equation below

$$
\mathrm{L}\left(\overline{\mathrm{x}}\left(\mathrm{I}_{\mathrm{d}}\right)\right)=\sum_{\mathrm{i}=1}^{5} \mathrm{P}_{\mathrm{f}}\left[\widetilde{\mathrm{B}}_{\tilde{\mathrm{i}}}, \overline{\mathrm{x}}\left(\mathrm{I}_{\mathrm{d}}\right)\right] \cdot \mathrm{D}_{\mathrm{i}}
$$

So, with different seismic fortification intensity Ids, the loss expectation curve L-Id can be drawn, shown as Fig.3-3. The loss expectation $L\left(\overline{\mathrm{x}}\left(\mathrm{I}_{\mathrm{d}}\right)\right)$ decreases with the increasing of seismic 
fortification intensity Id.

3.4 Decision-making of optimum seismic fortification level. After worked out the lowest construction costcurve Cmin-Id and loss expectation curve L-Id, then the illumination on Fig. 3 or single unbound variable minimization method can be used for calculating as per objective function

$$
\mathrm{W}\left(\overline{\mathrm{x}}\left(\mathrm{I}_{\mathrm{d}}\right)\right) \rightarrow \min
$$

Get the optimum seismic fortification intensity, which is corresponding to the lowest point of curve $W\left(\bar{x}\left(I_{d}\right)\right)$, i.e., the optimum seismic fortification level shall be finally decided.

Take a $110 \mathrm{kV}$ new-built substation as an example, it was designed and built in degree 7 fortificationlevel, with equipment purchasing cost 21.1712 million Yuan RMB, equipment installing cost 2.1815 million Yuan RMB, building construction cost 5.5695 million Yuan RMB, and others6.4022 million Yuan RMB, total investment for this substation was estimated about 35.3244 million Yuan RMB. Its optimum seismic fortification level was finally appraised in seismic fortification intensity 6,7,8, and 9 degrees, see Fig.4-32 for the optimum seismic fortification level decision-making graph for this substation.

For substations under different seismic fortification intensities, the estimation of construction cost at a low intensity area depends on equipment installation cost and others, rather than equipment purchasing cost, equipment installation cost, building construction cost and others at high earthquake intensity area. The loss of substation caused by earthquake includes direct loss and indirect loss. The direct loss decreases with the increasing of seismic fortification intensity, relates to seismic reliability and construction cost of substations themselves, the indirect loss further concerns with direct loss, for the verification is applied to but a substation, its acting range is uniform.

Seen from Fig.2, this substation, despite its seismic fortification was designed up to degree 7, its optimum seismic fortification level is degree 8.Seen from Code for Seismic Design of Electrical Installations(GB 50260 - 2013), the design basic acceleration of a degree 8fortification is twice that of degree 7.This is almost the ratio between a peak acceleration at 50 -year exceeding probability $2 \%$ and a peak acceleration at 50-year exceeding probability $10 \%$.

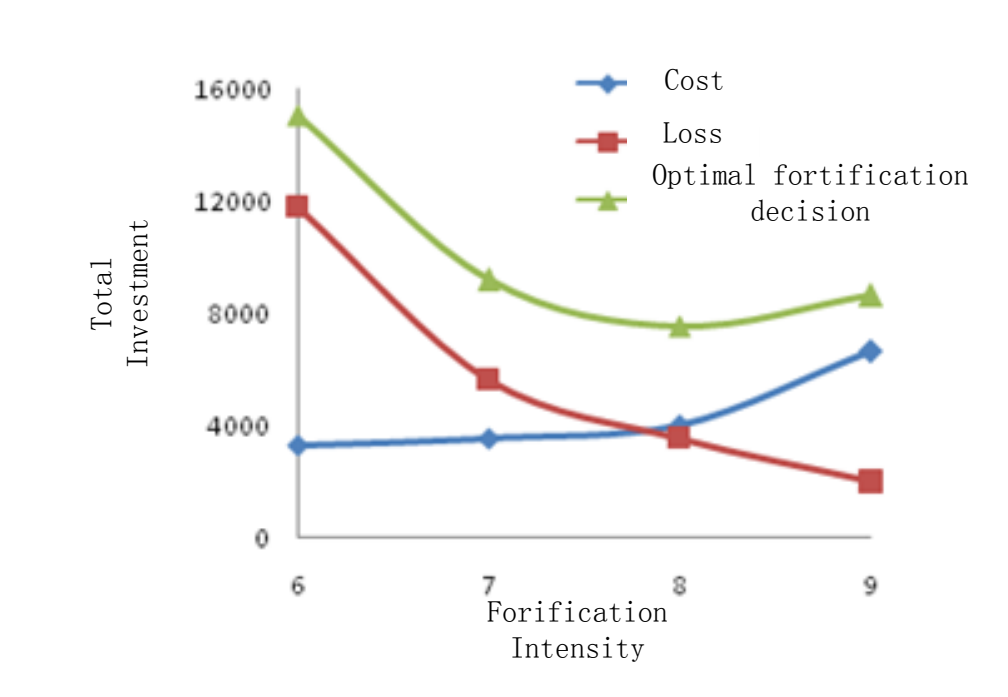

Fig.2 optimum seismic fortification level decision-making graph for an $110 \mathrm{kV}$ substation 
Furthermore, for grade VI, if an electric equipment increases its seismic fortification intensity 1 degree, then its corresponding 50-year exceeding probability ranges between $3 \%$ and $2 \%$; for grade VII, and grade VIII areas, if increasing seismic fortification intensity 1 degree, then the corresponding 50-year exceeding probability is between $2 \%$ and $1 \%$, approximate $1 \%$.Considering a medium-rigid site, and importance of power facilities, the design of 50-year exceeding probability shall be between $5 \%$ and $2 \%$, so the seismic fortification level for power grid is recommended as 50 -year exceeding probability $2 \%$.

\section{Seismic reliability and seismic failure degree}

The electrical equipment usually suffer brittle failure, their limit state equations are linear, their seismic reliability shall be calculated with a first-order second-moment method, assume that both equipment resistance and response should obey the law of Gaussian distribution, then the seismic reliability index $\beta$, failure probability $P_{f}$ andreliability $P_{r}$ are

$$
\begin{gathered}
\beta=\frac{\mu_{R}-\mu_{S}}{\sqrt{\sigma_{R}^{2}+\sigma_{S}^{2}}} \\
P_{f}=\phi(-\beta)=1-\phi(\beta) \\
P_{r}=\phi(\beta)
\end{gathered}
$$

Where, $\phi(\bullet)$ is the standard Gaussian Distribution function, $\mu_{R}$ and $\sigma_{R}$ are respectively the mean value and mean standard deviation of equipment resistance $R, \sigma_{R}$ and $\sigma_{S}$ are respectively the mean value and mean standard deviation of response[9].After worked out the mean value and variance of response at weak points of electrical equipment affected, the equipment reliability and failure probability can be calculated.

This paper takes typical electrical equipment for analyzing their seismic reliabilities under type $\mathrm{I}_{0}, \mathrm{I}_{1}, \mathrm{II}$, and III sites by a first-order second-moment method as mentioned above.

4.1 How to select the earthquake acceleration value. Our country's prevailing seismic group motion parameter zonation map only offers the peak ground acceleration at 50-year exceeding probability $10 \%$, but many designers pay much attention on how to get the peak ground acceleration value at 50-year exceeding probability $2 \% \sim 3 \%$.Seen from standard89 version and relating documents, a large earthquake is average 1 degree higher than that of medium earthquake, for peak acceleration, large earthquake is twice that of medium one [10].Seen from version 01seismic group motion parameter zonation map, a large earthquake is 1.6 1.7 times that of medium one [11].For higher safety of equipment, a peak ground acceleration at 50 -year exceeding probability $2 \%$ is feasible, shown as Tab.2.

Tab.2peak ground acceleration under different exceeding probabilities

\begin{tabular}{ccccccc}
\hline $\begin{array}{c}50 \text {-year } \\
\text { exceeding } \\
\text { probability }\end{array}$ & $\begin{array}{c}\text { Degree } \\
\text { VI }\end{array}$ & Degree VII & $\begin{array}{c}\text { Degree } \\
\text { VIII }\end{array}$ & $\begin{array}{c}\text { Degree } \\
\text { IX }\end{array}$ \\
\hline $10 \%$ & $0.5 \mathrm{~g}$ & $0.1 \mathrm{~g}$ & $0.15 \mathrm{~g}$ & $0.2 \mathrm{~g}$ & $0.3 \mathrm{~g}$ & $0.4 \mathrm{~g}$ \\
$2 \%$ & $0.1 \mathrm{~g}$ & $0.2 \mathrm{~g}$ & $0.3 \mathrm{~g}$ & $0.4 \mathrm{~g}$ & $0.5 \mathrm{~g}$ & $0.6 \mathrm{~g}$ \\
\hline
\end{tabular}


4.2 Seismic reliability of voltage transformer. $500 \mathrm{kV}$ voltage transformer has 3 groups of hollow porcelain cylinder and pad. Each pitch of cylinder is $1.8 \mathrm{~m}$ high, and pad $0.639 \mathrm{~m}$ high. The porcelain bush is OD $0.355 \mathrm{~m}$ and ID $0.265 \mathrm{~m}$, this equipment is $6.039 \mathrm{~m}$ high, total weight $2184.6 \mathrm{~kg}$, shown as Fig.3.The Young's modulus of porcelain takes $110 \mathrm{GPa}$.Its bottom is cemented. No support on the model, its magnification coefficient takes 1.2, and calculates by response spectrum method.

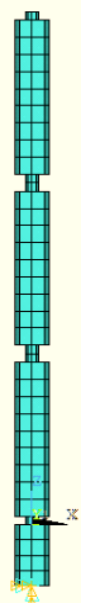

Fig.3 model of voltage transformer

The seismic reliability of 500kVordinary porcelaintransformer is basically insusceptible to classification of design earthquake, with identical seismic reliabilities for both type II, and type III sites. At the peak acceleration $0.1 \mathrm{~g}$ and $0.2 \mathrm{~g}$, the reliability is almost $100 \%$. At the peak acceleration up to $0.3 \mathrm{~g}$, the lowest reliability presents at type III site, which falls to $93.7 \%$. At $0.4 \mathrm{~g}$, the lowest reliability is also up to $70 \%$ and above, at peak acceleration $0.5 \mathrm{~g}$ and $0.6 \mathrm{~g}$, the reliability keeps falling, with lowest values respectively $47.2 \%$ and $28.4 \%$, shown as Fig.4.

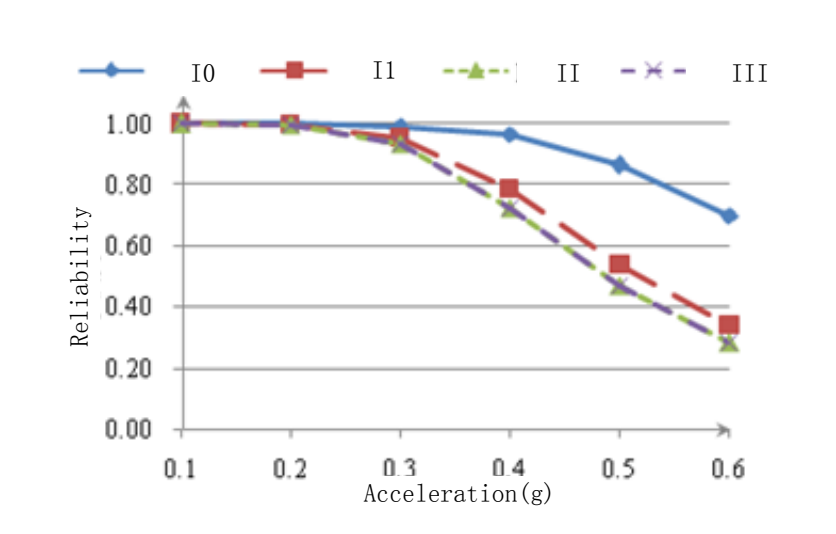

Fig.4Earthquake reliabilities of ordinary porcelain voltage transformers 4.3 Seismic reliabilities of disconnectors. 220kVdisconnectorhas 3 groups of solid porcelain cylinders and 1 steel-pipe support. Each porcelain cylinder group has two segments, the upper one is $\mathrm{R} 0.06 \mathrm{~m}$, the lower one is $\mathrm{R} 0.07 \mathrm{~m}$, the disconnector is $2.915 \mathrm{~m}$ high, total $214.03 \mathrm{~kg}$, its support is $3.50 \mathrm{~m}$ high, with the Young's modulus of porcelain100Gpa, shown as Fig.5. 


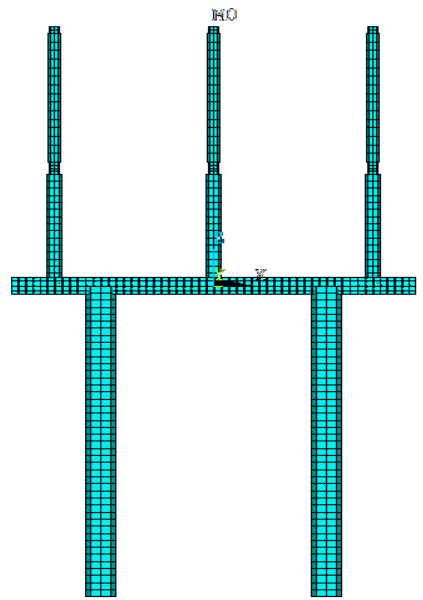

Fig.5 model of disconnector

For $220 \mathrm{kV}$ disconnector, its seismic reliability is basically insusceptible to classification of design earthquake, the reliability of equipment at type I0 site is basically equal to those in other types of sites. At $0.1 \mathrm{~g}$, its reliability is still up to about $100 \%$, with equipment completely intact. If the acceleration is up to $0.2 \mathrm{~g}$, its mean value lowers to $78.5 \%$, approximate to $80 \%$. Then if its acceleration is up to $0.3 \mathrm{~g}$,the reliability level falls abruptly, so far as to that of type $\mathrm{I} 0$ site been fallen to $40 \%$ and below, with mean value $28.5 \%$.after $0.4 \mathrm{~g}$, the reliability level completely falls to $10 \%$ and below, at $0.5 \mathrm{~g}$, its lowest value is $3.5 \%$, at $0.6 \mathrm{~g}$, its lowest value is $1.8 \%$, shown as Fig.6.

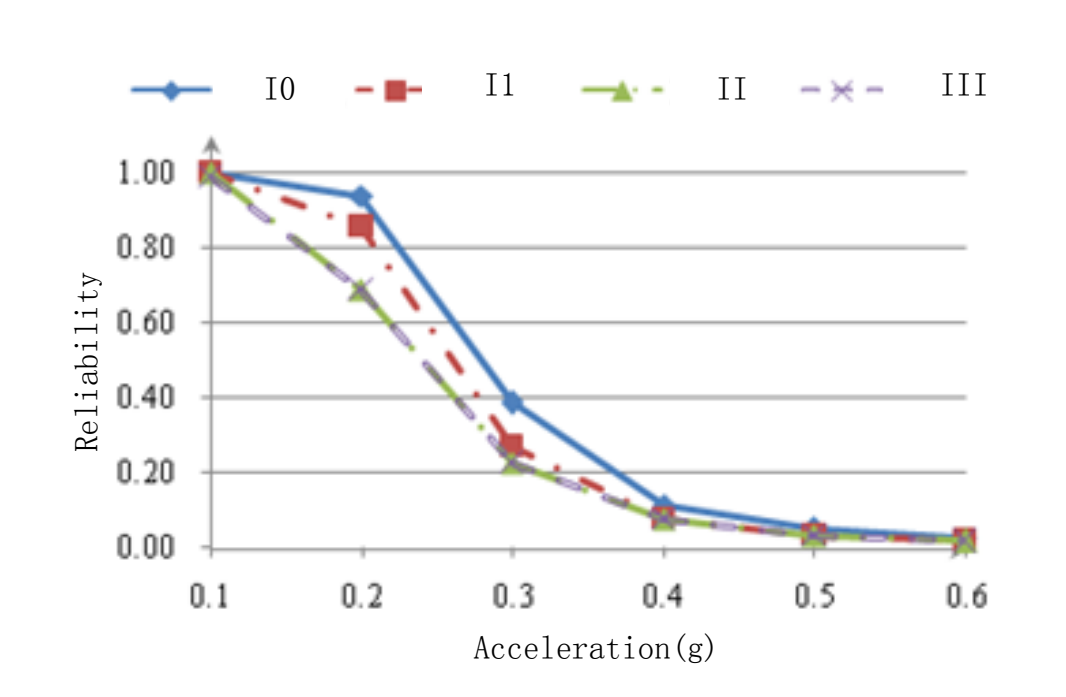

Fig.6Seismic reliabilities of $220 \mathrm{kV}$ ordinary porcelain disconnectors

4.4 Seismic failure degree. According to the seismic reliability of electrical equipment, the classification of failure to power grid facilities defines as per seismic reliability, including three types of basically intact, moderate, severe and destroy, with corresponding reliabilities as followings:

(1)Basically intact: equipment components and parts are intact, or individually slightly damaged, suitable for continuous service without repair. The range of seismic reliability is $0.00 \leq \operatorname{Pr}<0.05$;

(2) Moderate failure: a few equipment components and parts are spotted with slight fracture, and most of them with obvious cracks, usually unsuitable for continuous service without repair, the seismic reliability ranges $0.05 \leq \operatorname{Pr}<0.70$; 
(3) Severe failure and destroy: most of components have severe failures, uneasy or unable reusing, with seismic reliability ranging $0.70 \leq \operatorname{Pr}<1.00$.

Wherein, some quantitative words are defined as below:

(1) The "individual" is $5 \%$ and below;

(2) The "minority" is $5 \% \sim 45 \%$;

(3) The "majority" is $40 \% \sim 70 \%$;

(4) The "most" is $60 \% \sim 90 \%$.

\section{Grading of seismic fortification}

Seen from the degree of seismic failure to typical electrical equipment, classify the seismic capacity into three grade: $0.1 \mathrm{~g}$ and below is specified as the first grade, a low grade of seismic verification level, which is corresponding to seismic fortification intensity magnitude VI and below area, considering provisions of Code for Seismic Design of Electrical Installations(GB50260-96): electrical equipment $330 \mathrm{kV}$ and above shall have seismic design under seismic fortification grade VII and above, electrical equipment $220 \mathrm{kV}$ and below shall have seismic design under seismic fortification grade VIII and above, with peak acceleration value $0.1 \mathrm{~g}$; take $0.1 \mathrm{~g} \sim 0.4 \mathrm{~g}$ as the second verification level for moderate seismic failure, which is corresponding to seismic fortification intensity magnitude VII VIII zones, with peak acceleration value $0.4 \mathrm{~g}$; take $0.4 \mathrm{~g}$ and above as the third verification level for severe seismic failure, which is corresponding to seismic fortification intensity magnitude IX and above zones, with peak acceleration value $0.6 \mathrm{~g}$.

\section{Conclusions}

Our country's prevailing substation electrical equipment seismic fortification zonation comes from Seismic Ground Motion Parameter Zonation Map of China(GB18306-2001), which is mainly suitable for seismic design of buildings, because the building structure is significantly different from electrical equipment on materials, structural type and production process,especially more precision the classification for buildings is more unfavorable for massive and batch production of electrical equipment.

By analyzing the seismic fortification level of electrical equipment with optimum seismic fortification level decision-making procedure, we recommended a 50-year exceeding probability $2 \%$.

Seen from results of electrical equipment seismic reliability calculations, and seismic failure classification for typical high voltage electrical equipment, our country's high voltage electrical equipment have three seismic fortification classification of high, medium and low grades.0.1 $\mathrm{g}$ and below belongs to low seismic verification level, with acceleration $0.1 \mathrm{~g} ; 0.1 \mathrm{~g} \sim 0.4 \mathrm{~g}$ belongs to medium level, with peak acceleration value $0.4 \mathrm{~g} ; 0.4 \mathrm{~g}$ and above belongs to high level, with peak acceleration value $0.6 \mathrm{~g}$.

\section{References}

[1]GB50260-2013.Code for Seismic Design of Electrical Installations[S].Beijing:China Planning Press, 2013.

[2]GB18306-2001.Seismic Ground Motion Parameter Zonation Map of China [S].Beijing: China 
standard press, 2001.

[3]GB 50011 - 2010.Code for Seismic Design of Buildings[S].Beijing: China Building Industry Press, 2010 .

[4] JEAG 5003-1998.Guide of Seismic Design for Electrical Equipment[S].Japan Electrical Technology Standard Investigation Committer,1998.

[5] IEC62271-2:2003.High-voltage switchgear and control gear-Part 2: Seismic qualification for rated voltages of $72.5 \mathrm{kV}$ and above[S].

[6]IEEE Std 693-2005.IEEE Recommended Practice for Seismic Design of Substations[S].IEEE Power Engineering Society,2005.

[9] Chen Huai, Li Jie. Method for analyzing the seismic reliability of high voltage electrical equipment[J].World earthquake engineering,2006,16(2):19-23.

Chen Huai, Li Jie. Seismic Reliability Analysis of High Voltage Electrical Equipments[J].World Information on Earthquake Engineering,2006,16(2):19-23.

[10] China Academy of Building Research. Provisions of Code for Seismic Design of Buildings[M].Beijing: Liaoning Science Press,1990,1-2.

[11] State Standardization Administration Committee.GB18306-2001 textbook of Seismic Ground Motion Parameter Zonation Map of China[M].Beijing: China standard press,2001,106. 